\title{
Differences in the burden of psychiatric comorbidity in MS vs the general population
}

\section{OPEN}

Ruth Ann Marrie, MD, $\mathrm{PhD}$

John D. Fisk, PhD

Helen Tremlett, PhD

Christina Wolfson, PhD

Sharon Warren, PhD

Aruni Tennakoon, MSc

Stella Leung, MSc

Scott B. Patten, MD,

$\mathrm{PhD}$

On behalf of the CIHR

Team in the

Epidemiology and

Impact of Comorbidity on Multiple Sclerosis

Correspondence to Dr. Marrie:

rmarrie@hsc.mb.ca

Supplemental data at Neurology.org

\section{ABSTRACT}

Objective: We aimed to compare the incidence and prevalence of psychiatric comorbidity in the multiple sclerosis (MS) population and in controls matched for age, sex, and geographic area.

Methods: Using population-based administrative health data from 4 Canadian provinces, we identified 2 cohorts: 44,452 persons with MS and 220,849 controls matched for age, sex, and geographic area. We applied validated case definitions to estimate the incidence and prevalence of depression, anxiety, bipolar disorder, and schizophrenia from 1995 to 2005. We pooled the results across provinces using meta-analyses.

Results: Of the MS cases, 31,757 (71.3\%) were women with a mean (SD) age at the index date of 43.8 (13.7) years. In 2005, the annual incidence of depression per 100,000 persons with MS was 979 while the incidence of anxiety was 638, of bipolar disorder was 328, and of schizophrenia was 60. The incidence and prevalence estimates of all conditions were higher in the MS population than in the matched population. Although the incidence of depression was higher among women than men in both populations, the disparity in the incidence rates between the sexes was lower in the MS population (incidence rate ratio 1.26; 95\% confidence interval: 1.07-1.49) than in the matched population (incidence rate ratio 1.50; 95\% confidence interval: 1.21-1.86). Incidence rates were stable over time while prevalence increased slightly.

Conclusions: Psychiatric comorbidity is common in MS, and more frequently affected the MS population than a matched population, although the incidence was stable over time. Men with MS face a disproportionately greater relative burden of depression when they develop MS than women. Neurology ${ }^{\circledR}$ 2015;85:1972-1979

\section{GLOSSARY}

$\mathbf{C I}=$ confidence interval; ICD-9 = International Classification of Diseases, Ninth Revision; ICD-10-CA = International Classification of Diseases, Tenth Revision, Canada; $\mathbf{M S}=$ multiple sclerosis.

Depression and anxiety reduce quality of life in multiple sclerosis (MS), ${ }^{1,2}$ and depression is associated with reduced persistence to disease-modifying therapy. ${ }^{2}$ While such adverse effects of psychiatric comorbidity are recognized in MS, the epidemiology of psychiatric comorbidity remains poorly understood. ${ }^{3}$

Prevalence estimates for depression (4.98\%-58.9\%), anxiety $(1.2 \%-44.6 \%)$, and bipolar disorder $(0 \%-16.2 \%)$ vary widely in the MS population. ${ }^{3}$ Few studies have evaluated the prevalence of schizophrenia. ${ }^{4-7}$ Most studies suggest that depression, anxiety, and bipolar disorder affect the MS population more often than the general population, ${ }^{4}$ but findings regarding schizophrenia conflict. ${ }^{3,8}$ Many of the studies that evaluated the prevalence of psychiatric

\footnotetext{
From the Departments of Internal Medicine (R.A.M.) and Community Health Sciences (R.A.M., S.L.), University of Manitoba, Winnipeg; Departments of Psychiatry and Medicine (J.D.F.), Dalhousie University, Halifax; Department of Medicine (Neurology) (H.T.), University of British Columbia, Vancouver; Department of Epidemiology and Biostatistics and Occupational Health (C.W.), McGill University, Montreal; Faculty of Rehabilitation Medicine (S.W.), University of Alberta, Edmonton; and Department of Community Health Sciences (S.B.P.), University of Calgary, Canada.

CIHR Team in the Epidemiology and Impact of Comorbidity on Multiple Sclerosis coinvestigators are listed on the Neurology ${ }^{\circledR}$ Web site at Neurology.org.

Go to Neurology.org for full disclosures. Funding information and disclosures deemed relevant by the authors, if any, are provided at the end of the article. The Article Processing Charge was paid by the Canadian Institutes for Health Research.

This is an open access article distributed under the terms of the Creative Commons Attribution-NonCommercial-NoDerivatives License 4.0 (CC BY-NC-ND), which permits downloading and sharing the work provided it is properly cited. The work cannot be changed in any way or used commercially.
} 
comorbidities were not population-based. Furthermore, comparisons to other populations have failed to use concurrent controls. Although incidence estimates are necessary to determine risk, incidence estimates for psychiatric comorbidities are even more limited than are prevalence estimates, being reported only for depression. ${ }^{9}$

We aimed to estimate the incidence and prevalence of psychiatric comorbidity in MS, including sex-specific estimates, and temporal trends using population-based administrative data. We compared these findings in the MS population to those observed in controls matched for age, sex, and geographic area.

METHODS Study populations. We adopted an approach used by the Canadian Network for Observational Drug Effect Studies. ${ }^{10}$ Privacy regulations prevent line-level data from leaving the province of origin. Thus, we applied a common protocol to datasets from 4 Canadian provinces, British Columbia (BC), Manitoba (MB), Quebec (QC), and Nova Scotia (NS), where nearly 43\% of the Canadian population resides (http://www.statcan.gc.ca/tablestableaux/sum-som/101/cst01/demo02a-eng.htm; accessed April 1, 2015), then pooled the provincial estimates using meta-analyses. Provinces were selected based on the feasibility of data access. In each province, we conducted a cohort study using anonymized administrative data, which captured virtually all residents throughout the study period. Within each province, we used unique personal identification numbers to link population registries and hospital and physician claims for the years 1990 to 2010, except in BC where data extended to 2008 and 2009. ${ }^{11-13}$ Each population registry records sex, dates of birth and death, dates of health care coverage (provincial residency), and postal code. Hospital claims include dates of admission and discharge and diagnosis codes classified using the ICD-9 or ICD-10-CA system. Physician claims (for inpatient and outpatient care) include the date of service and physician-assigned diagnosis classified using $I C D-9$ codes.

Standard protocol approvals, registrations, and patient consents. We obtained ethics approval and approval to access administrative data in each province.

We identified all persons with MS as those with $\geq 3$ hospital or physician claims for MS (ICD-9/10 = 340/G39) using an administrative case definition validated in $\mathrm{MB}$ and NS..$^{14,15} \mathrm{We}$ also selected a matched cohort from the general population after excluding anyone with any diagnostic codes (ICD-9 and -10) for demyelinating disease. For each case, we identified up to 5 controls matched on sex, year of birth, and region of residence (full postal code or first 3 digits of postal code if full match impossible). For each person with MS, we assigned the date of their first demyelinating disease claim as the "date of diagnosis," and the same date (index date) was assigned to their matched controls.

Psychiatric comorbidity. Administrative case definitions for depression, anxiety, bipolar disorder, and schizophrenia developed by our group and validated in MB and NS were applied to identify affected individuals in both populations (e-Methods on the Neurology ${ }^{\circledR}$ Web site at Neurology.org). ${ }^{4,16}$ Since these disorders are conceptualized as lifelong, recurrent conditions, once a person met the case definition for the selected comorbidity, he or she was considered affected in all subsequent years while alive and resident in their province. Prevalence was estimated each year using midyear population figures as the denominators. To estimate incidence, we required a 5-year run-in period before the first comorbidity claim. In the MS cohort, a comorbidity case was defined as incident if the first comorbidity claim occurred after the date of MS diagnosis, while for the matched cohort, a comorbidity case was defined as incident if the first comorbidity claim occurred after the index date assigned to their matched case. Artifactual drops in incidence may occur at the end of a study period because new cases do not have sufficient follow-up time to meet the case definition. Therefore, we report incidence and prevalence for 1995 through 2005. We used the direct method to age-standardize findings to the 2001 Canadian population (closest to the study midpoint and consistent with earlier work). We calculated $95 \%$ confidence intervals (CIs) assuming a Poisson distribution. Cell sizes $<5$ were suppressed, preventing direct modeling of crude rates. Therefore, we modeled age-standardized incidence and prevalence using Poisson regression, adjusting for year and sex. ${ }^{17}$ This approach controls for age effects without introducing age in the model as a covariate. ${ }^{17}$ We report pooled incidence rates, prevalence, adjusted rate ratios, and their 95\% CIs. Given that a systematic review reported heterogeneity of prevalence estimates of psychiatric comorbidity in MS, ${ }^{3}$ province-specific estimates were pooled using random-effects meta-analysis and we report $I^{2}$ (a measure of heterogeneity) and $\tau^{2}$ (a measure of between-study variance; e-Methods). Forest plots illustrate variation in incidence and prevalence estimates across provinces, and in rate ratios for the association between comorbidity and study population.

Analyses were performed using SAS version 9.3 (SAS Institute Inc., Cary, NC) and using an Excel spreadsheet for metaanalyses. ${ }^{18}$

RESULTS We identified 44,452 MS cases, and 220,849 matched controls (table e-1). Of the MS cases, $31,757(71.4 \%)$ were women with a mean (SD) age at the index date of 43.8 (13.7) years.

Depression. In 2005, the crude incidence (95\% CI) of depression in the MS population was 979 per 100,000 persons or $0.98 \%(0.81 \%-1.15 \%$, figure e- 1$)$ overall $(0.94 \%, 0.80 \%-1.08 \%$ in women; $1.02 \%, 0.78 \%-$ $1.25 \%$ in men), while it was $0.72 \%(0.67 \%-0.76 \%)$ in the matched population (figure e-2). Adjusting for year and sex, the age-standardized incidence of depression was $71 \%$ higher in the MS population than in the matched population (table 1, figure 1). The incidence of depression was higher in women than in men but was stable over time.

In 2005, the crude prevalence of depression in the MS population was $20.1 \%$ (19.5\%-20.6\%, figure e-3) overall $(21.8 \%, 21.0 \%-22.5 \%$ in women; $15.2 \%$, $14.4 \%-16.1 \%$ in men), while it was $11.9 \%(11.8 \%-$ $12.1 \%$ ) in the matched population (figure e-4). Adjusting for year and sex, the age-standardized prevalence of depression was higher in the MS population than the matched population (table 1, figure e-5). The prevalence of depression was higher in women than in men and increased slightly over time.

We observed an interaction between sex and population. The incidence of depression was $26 \%$ 
Table 1 Depression: Adjusted associations of incidence and prevalence with the study population, sex, and time

\begin{tabular}{|c|c|c|c|c|c|c|c|}
\hline & BC, RR (95\% Cl) & MB, RR (95\% CI) & QC, RR (95\% Cl) & NS, RR (95\% CI) & $\tau^{2}$ & $I^{2}$ (p value) & $\begin{array}{l}\text { Random-effects } \\
\text { summary } \\
\text { estimate, RR } \\
(95 \% \mathrm{Cl})\end{array}$ \\
\hline \multicolumn{8}{|l|}{ Incidence } \\
\hline $\begin{array}{l}\text { MS population } \\
\text { vs matches }\end{array}$ & 2.10 (1.94-2.27) & 1.63 (1.42-1.87) & 1.89 (1.67-2.13) & $1.26(1.05-1.50)$ & 0.34 & $90.3(<0.0001)$ & $1.71(1.40-2.08)$ \\
\hline Women vs men & 1.49 (1.38-1.60) & 1.61 (1.41-1.84) & 1.23 (1.09-1.38) & 1.02 (0.86-1.50) & 0.19 & 81.4 (0.0011) & 1.36 (1.17-1.58) \\
\hline Time/y & 0.98 (0.97-0.99) & 0.99 (0.98-1.02) & 1.09 (1.06-1.11) & $0.86(0.84-0.89)$ & 0.002 & $98.1(<0.0001)$ & $0.98(0.91-1.05)$ \\
\hline \multicolumn{8}{|l|}{ Prevalence } \\
\hline $\begin{array}{l}\text { MS population } \\
\text { vs matches }\end{array}$ & 1.95 (1.84-2.07) & 1.70 (1.62-1.79) & 1.97 (1.83-2.13) & 1.59 (1.53-1.66) & 0.07 & $93.2(<0.0001)$ & 1.79 (1.61-1.99) \\
\hline Women vs men & $1.61(1.52-1.71)$ & 1.56 (1.48-1.63) & $1.20(1.11-1.28)$ & $1.57(1.51-1.64)$ & 0.05 & $93.9(<0.0001)$ & 1.48 (1.33-1.65) \\
\hline Time/y & 1.08 (1.07-1.09) & 1.06 (1.05-1.07) & 1.12 (1.11-1.13) & 1.02 (1.01-1.02) & 0.0009 & $99.2(<0.0001)$ & 1.07 (1.02-1.12) \\
\hline
\end{tabular}

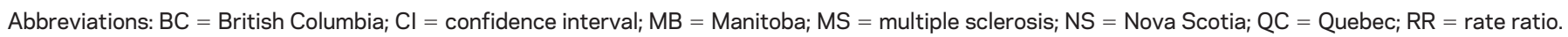

higher among women than men with MS, but $50 \%$ higher among women than men in the matched population (table e-2). Among women, the incidence of depression was $59 \%$ higher in the MS population than in the matched population, but among men was $93 \%$ higher in the MS than in the matched population (table e-3). The findings were similar for the prevalence of depression (tables e-2 and e-3).
Anxiety disorder. In 2005, the crude incidence of anxiety disorder in the MS population was 638 per 100,000 persons or $0.64 \%(0.54 \%-0.73 \%$, figure e-6) overall $(0.74 \%, 0.62 \%-0.86 \%$ in women; $0.33 \%, 0.20 \%-0.46 \%$ in men), while it was $0.42 \%$ $(0.39 \%-0.45 \%)$ in the matched population (figure e-7). Adjusting for year and sex, the age-standardized incidence of anxiety disorder was $42 \%$ higher in the MS than matched population (table 2, figure 1). The

Figure 1 Forest plots of the association of the incidence of psychiatric comorbidity with study population (multiple sclerosis vs matched)

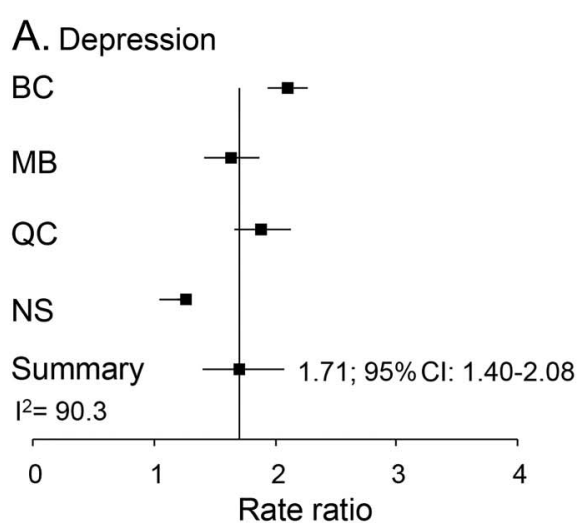

C. Bipolar disorder

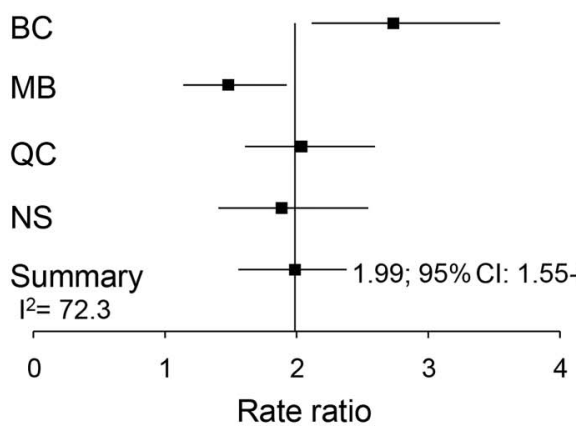

B. Anxiety

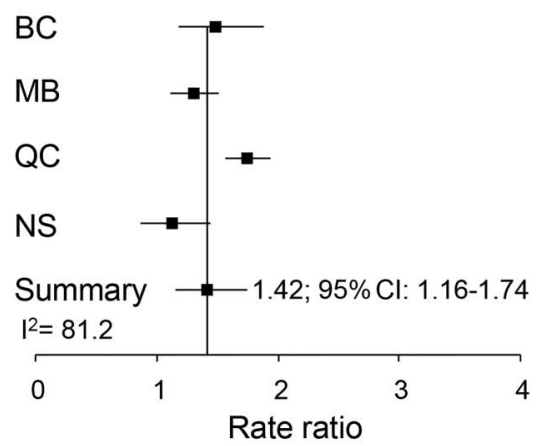

D. Schizophrenia

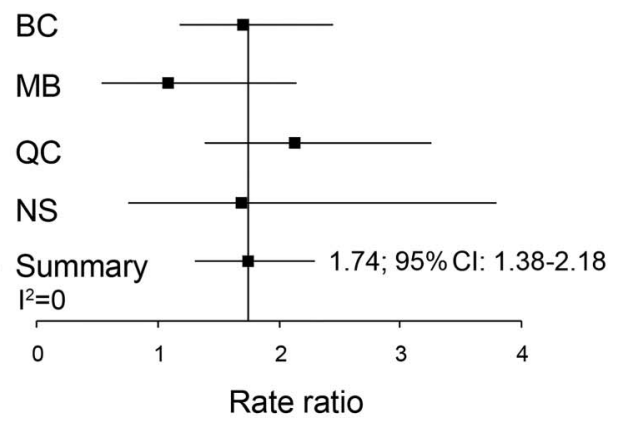

$\mathrm{BC}=$ British Columbia; $\mathrm{Cl}=$ confidence interval; $\mathrm{MB}=$ Manitoba; NS = Nova Scotia; $\mathrm{QC}=$ Quebec. 
Table 2 Anxiety disorder: Adjusted associations of incidence and prevalence with the study population, sex, and time

\begin{tabular}{|c|c|c|c|c|c|c|c|}
\hline & BC, RR (95\% Cl) & MB, RR (95\% Cl) & QC, RR $(95 \% \mathrm{Cl})$ & NS, RR (95\% Cl) & $\tau^{2}$ & $I^{2}$ (p value) & $\begin{array}{l}\text { Random-effects summary } \\
\text { estimate, RR }(95 \% \mathrm{CI})\end{array}$ \\
\hline \multicolumn{8}{|l|}{ Incidence } \\
\hline MS population vs matches & $1.49(1.18-1.89)$ & $1.30(1.11-1.51)$ & $1.75(1.57-1.94)$ & $1.13(0.87-1.45)$ & 0.44 & $81.2(0.0012)$ & $1.42(1.16-1.74)$ \\
\hline Women vs men & $2.25(1.75-2.89)$ & $1.76(1.50-2.07)$ & $1.21(1.09-1.34)$ & $1.35(1.04-1.74)$ & 0.57 & $89.7(<0.0001)$ & $1.58(1.20-2.09)$ \\
\hline Time/y & $1.03(0.99-1.07)$ & $1.01(0.99-1.04)$ & $1.07(1.06-1.09)$ & $0.88(0.85-0.92)$ & 0.004 & $96.7(<0.0001)$ & $1.00(0.93-1.07)$ \\
\hline \multicolumn{8}{|l|}{ Prevalence } \\
\hline Women vs men & $2.05(1.97-2.14)$ & $1.65(1.59-1.71)$ & $1.22(1.17-1.27)$ & $1.73(1.68-1.78)$ & 0.03 & $98.7(<0.0001)$ & $1.58(1.35-1.85)$ \\
\hline Time/y & $1.08(1.07-1.09)$ & $1.07(1.06-1.08)$ & $1.14(1.13-1.15)$ & $1.02(1.01-1.02)$ & 0.0009 & $99.4(<0.0001)$ & $1.08(1.02-1.13)$ \\
\hline
\end{tabular}

Abbreviations: $\mathrm{BC}=$ British Columbia; $\mathrm{Cl}=$ confidence interval; $\mathrm{MB}=$ Manitoba; $\mathrm{MS}=$ multiple sclerosis; $\mathrm{NS}=$ Nova $\mathrm{Scotia} ; \mathrm{QC}=\mathrm{Quebec}$;R $=$ rate ratio.

incidence of anxiety disorder was higher in women than in men and did not change over time.

In 2005, the crude prevalence of anxiety disorder in the MS population was $8.7 \%(8.4 \%-9.1 \%$, figure e-8) overall $(10.0 \%, 9.6 \%-10.5 \%$ in women; $4.9 \%$, $4.4 \%-5.4 \%$ in men), while it was $5.1 \%(4.9 \%$ $5.2 \%$ ) in the matched population (figure e-9). Adjusting for year and sex, the age-standardized prevalence of anxiety disorder was 58\% higher in the MS population than in the matched population (table 2 , figure e-10). The prevalence of anxiety disorder was higher in women than in men and increased slightly over time ( $8 \%$ per year). There was no interaction between sex and study population for incidence or prevalence.

Bipolar disorder. In 2005, the crude incidence of bipolar disorder in the MS population was 328 per 100,000 persons or $0.33 \%(0.26 \%-0.39 \%$, figure e- 11$)$ overall $(0.27 \%, 0.20 \%-0.34 \%$ in women; $0.47 \%, 0.31 \%-0.62 \%$ in men). Although the incidence of bipolar disorder was lower in women than in men with MS in 2005, it was higher in women $(0.38 \%, 0.35 \%-0.41 \%)$ than in men $(0.32 \%$, $0.28 \%-0.37 \%)$ if averaged over the study period.
The incidence was $0.16 \%(0.14 \%-0.18 \%$, figure e- 12$)$ in the matched population. Adjusting for year and sex, the age-standardized incidence of bipolar disorder was $99 \%$ higher in the MS than in the matched population (table 3, figure 1). The incidence of bipolar disorder was higher in women than in men (although this was not statistically significant) and did not change over time.

In 2005, the crude prevalence of bipolar disorder in the MS population was $4.7 \%$ (4.4\%-4.9\%, figure e-13) overall $(5.0 \%, 4.7 \%-5.3 \%$ in women; $3.9 \%$, $3.5 \%-4.3 \%$ in men), while it was $2.3 \%(2.2 \%-$ $2.3 \%$, figure e-14) in the matched population. Adjusting for year and sex, the age-standardized prevalence of bipolar disorder was 2-fold higher in the MS population than in the matched population (table 3, figure e-15). The prevalence of bipolar disorder was higher in women than in men and increased slightly over time ( $8 \%$ per year). There was no interaction between sex and study population for incidence or prevalence.

Schizophrenia. In 2005, the age-standardized incidence of schizophrenia in the MS population was $0.060 \%$ (0.031\%-0.080\%, figure e-16) overall $(0.072 \%$,

Table 3 Bipolar disorder: Adjusted associations of incidence and prevalence with the study population, sex, and time

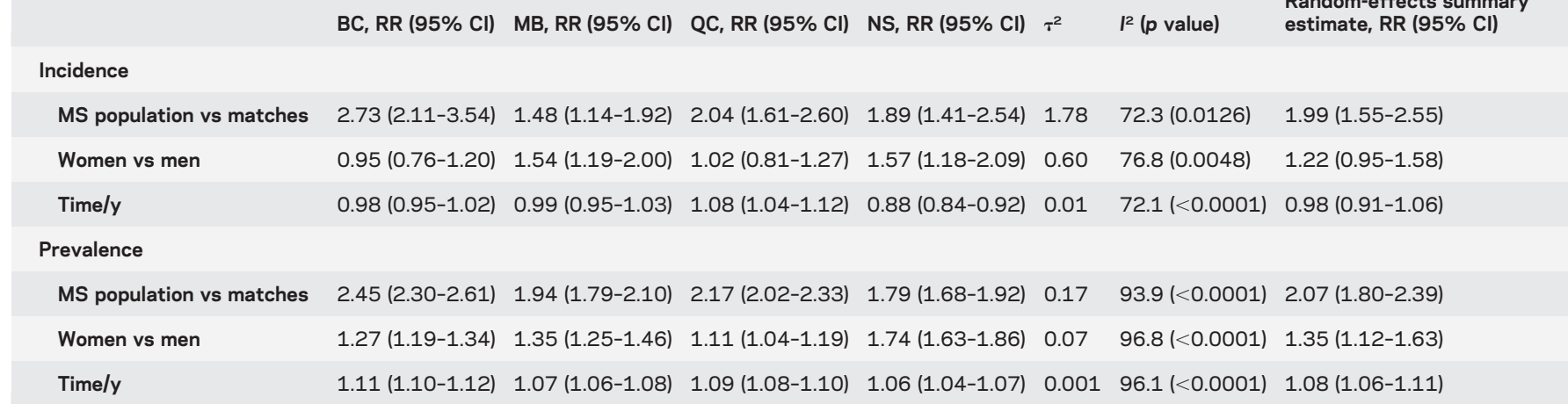

Abbreviations: $\mathrm{BC}=$ British Columbia; $\mathrm{Cl}=$ confidence interval; $\mathrm{MB}=$ Manitoba; $\mathrm{MS}=$ multiple sclerosis; $\mathrm{NS}=$ Nova $\mathrm{Scotia} ; \mathrm{QC}=\mathrm{Quebec} ; \mathrm{RR}=$ rate ratio. 
$0.036 \%-0.11 \%$ in women; $0.011 \%, 0 \%-0.034 \%$ in men) vs $0.018 \%(0.011 \%-0.024 \%$, figure e- 17$)$ in the matched population (because of suppression of some cells, we could not pool crude incidence). Adjusting for year and sex, the age-standardized incidence of schizophrenia disorder was $74 \%$ higher in the MS population than in the matched population (table 4 , figure 1). The incidence of schizophrenia was lower in women than in men and the incidence declined slightly over time.

In 2005, the crude prevalence of schizophrenia in the MS population was $1.28 \%(1.15 \%-1.41 \%$, figure e- 18$)$ overall $(0.89 \%, 0.76 \%-1.02 \%$ in women; $1.22 \%, 0.97 \%-1.46 \%$ in men) vs $1.03 \%(0.99 \%-$ $1.08 \%$, figure e-19) in the matched population. Adjusting for year and sex, the age-standardized prevalence of schizophrenia was slightly higher in the MS population than in the matched population but this did not reach statistical significance (table 4, figure e-20). Unlike the other conditions, the prevalence of schizophrenia was lower in women than in men. Like the other conditions, the prevalence of schizophrenia increased slightly over time ( $4 \%$ per year). There was no interaction between sex and study population for incidence or prevalence.

DISCUSSION In this population-based study involving more than 250,000 Canadians, the incidence and prevalence of anxiety, bipolar disorder, depression, and schizophrenia were all higher in the MS population than in the matched population. Over time, the incidence rates of these comorbidities were stable (except for schizophrenia, which declined) while their prevalence increased slightly. In the MS and matched populations, women had a higher incidence and prevalence of depression, anxiety disorder, and bipolar disorder than men while the opposite was true for schizophrenia.

A systematic review found no prior studies that have reported the incidence of anxiety disorders, bipolar disorder, or schizophrenia in $\mathrm{MS},{ }^{3}$ making our findings unique. Two studies have reported the incidence of depression with estimates ranging from $4.0 \%$ in 1 year to $34.7 \%$ over 5 years. ${ }^{919}$ These estimates are higher than ours (979 per 100,000 persons), possibly reflecting methodologic differences. The clinic-based study identified incident depression using a self-report questionnaire and a self-reported history of no depression at baseline. ${ }^{19}$ The second study identified depression using a single ICD-10 code in an administrative database, a highly sensitive but less specific approach than our case definition. ${ }^{9}$

A meta-analysis of 8 population-based studies reported the prevalence of depression to be $23.7 \%$ (95\% CI: $17.4 \%-30.0 \%){ }^{3}$ similar to our findings of $20.1 \%$, while this same meta-analysis found a prevalence of anxiety disorder in MS of $21.9 \%$ (95\% CI: $8.76 \%-35.0 \%){ }^{3}$ However, when the 3 studies that used administrative data or other medical records to identify anxiety disorder were considered, ${ }^{20-22}$ the summary estimate was $15.4 \% \quad(95 \% \quad \mathrm{CI}: \quad 0 \%-$ $39.0 \%$ ), closer to our estimate of $8.7 \%$. Thus, our findings are similar to those from previous studies that have used comparable methods. For bipolar disorder, prior studies in MS have reported a lifetime prevalence ranging from $0 \%$ to $16.2 \% .^{3}$ However, the only population-based study, which found a prevalence of $5.83 \%$ in 2005 , was also conducted in the province of $\mathrm{MB}$, using fewer years of data; thus, similarities to the current findings $(4.7 \%)$ were expected. ${ }^{4}$ Previous studies of the prevalence of schizophrenia are few but prevalence estimates for schizophrenia range from $0 \%$ to $7.4 \%,{ }^{4-7}$ encompassing our estimate of $1.3 \%$.

We found that the incidence of all psychiatric comorbidities studied except schizophrenia was stable over time, while prevalence increased slightly. A survey of 9,282 Americans in the general population conducted between 2001 and 2003 reported a higher lifetime prevalence of psychiatric disorders in more

Table 4 Schizophrenia: Adjusted associations of incidence and prevalence with study population, sex, and time

\section{BC, RR (95\% Cl) MB, RR (95\% Cl) QC, RR (95\% Cl) NS, RR (95\% Cl) $\tau^{2} \quad I^{2}$ (p value)}

Incidence

MS population vs matches

Women vs men

Time/y

\section{(}

$1.70(1.18-2.44) \quad 1.08(0.54-2.14) \quad 2.13(1.39-3.26) \quad 1.69(0.75-3.80) \quad 2.56$

0.85 (0.59-1.21) 0.68 (0.34-1.37) $0.83(0.56-1.24) \quad 0.87(0.40-1.91) \quad 0.89$

$0.95(0.90-1.00) \quad 0.68(0.34-1.37) \quad 0.99(0.93-1.05) \quad 0.92(0.81-1.04) \quad 0.06$

Prevalence

MS population vs matches

Women vs men

Time/y

$1.24(1.17-1.31) \quad 1.03(0.96-1.12) \quad 1.49(1.37-1.61) \quad 0.79(0.72-0.86) \quad 0.05$

$0.78(0.74-0.82) \quad 0.87(0.80-0.94) \quad 0.61(0.57-0.66) \quad 0.93(0.85-1.01) \quad 0.02$

$1.06(1.05-1.07) \quad 1.03(1.02-1.05) \quad 1.04(1.03-1.05) \quad 1.01(0.99-1.03) \quad 0.001$

$\begin{array}{ll}\text { NA (0.43) } & 1.74(1.38-2.18) \\ \text { NA (0.95) } & 0.82(0.65-1.04) \\ \text { NA (0.47) } & 0.96(0.93-0.99)\end{array}$

Random-effects summary estimate, RR ( $95 \% \mathrm{Cl})$

$97.6(<0.0001) 1.11(0.87-1.41)$

$87.8(<0.0001) \quad 0.79(0.67-0.93)$

$89.4(<0.0001) \quad 1.04(1.02-1.05)$

Abbreviations: $\mathrm{BC}=$ British Columbia; $\mathrm{Cl}=$ confidence interval; $\mathrm{MB}=$ Manitoba; $\mathrm{MS}=$ multiple sclerosis; $\mathrm{NA}=$ not available; $\mathrm{NS}=\mathrm{Nova}$ Scotia; $\mathrm{QC}=$ Quebec; $\mathrm{RR}=$ rate ratio. 
recent cohorts. ${ }^{23}$ Prevalence may increase despite stable incidence because of earlier diagnosis or improving survival. Survival has improved in the MS and general populations over time, ${ }^{24}$ but we did not evaluate whether diagnosis of psychiatric comorbidities is occurring at earlier ages. We also assumed that our incident cases became prevalent cases for the entire study period, consistent with the current conceptualization of each of these disorders as lifelong, recurrent conditions.

The incidence and prevalence of psychiatric comorbidity varied considerably across provinces as shown by the forest plots. Therefore, the pooled estimate is valuable, but also should be interpreted cautiously. It represents a weighted average of the provincial estimates, but it is clear that there are differences (beyond chance variation) between provinces. The pooled randomeffects estimate is the center of an estimated distribution of provincial values. Global variation in the burden of depression and anxiety is recognized in the general population, ${ }^{25,26}$ and the Canadian Community Health survey suggested that the use of mental health services varies considerably nationwide. ${ }^{27}$ Some of the variation observed likely is related to the challenges of accurately distinguishing depression from anxiety based on administrative data when using 3-digit ICD codes. ${ }^{28}$ Nonetheless, our pooled estimates of the prevalence of depression, bipolar disorder, and schizophrenia are consistent with those reported for the Canadian population using other methods such as the Composite International Diagnostic Interview. ${ }^{29-31}$

The burden of all psychiatric disorders evaluated was higher in the MS population than in the matched population, and these estimates showed much less variation than the incidence and prevalence estimates. Our findings are consistent with the broader literature regarding depression, anxiety, and bipolar disorder in MS. ${ }^{3}$ The literature conflicts regarding the risk of schizophrenia in MS. Some studies, including ours, suggest an increased risk while others suggest no change in risk and a Swedish study reported a reduced risk. ${ }^{8}$ It is uncertain whether this reflects methodologic differences as several prior studies used administrative data, although differences in diagnostic coding by physicians and other factors may vary across jurisdictions.

Compared with men, women had a higher incidence and prevalence of depression, anxiety, and bipolar disorder in both populations. Worldwide, women have a higher lifetime and period prevalence of depression and anxiety, ${ }^{32}$ while men have a higher incidence and prevalence of schizophrenia. ${ }^{33}$ Thus, most of our findings are consistent with the literature in the general population regarding sex differences in psychiatric disorders. However, we found that women had a higher risk of bipolar disorder than men, which has not been reported in the MS population previously. ${ }^{3}$ A study using structured interviews reported that the most common bipolar disorder in MS was bipolar II disorder ${ }^{34}$; this may account for our findings as women and men in the general population have a similar risk of bipolar I disorder, while women have a higher incidence of bipolar II disorder. ${ }^{35} \mathrm{We}$ also found that the disparity in the incidence rates between the sexes for depression was smaller in the MS than in the matched population. Previous findings have been inconsistent, ${ }^{36-38}$ but one populationbased Canadian survey showed similar associations. ${ }^{38}$ This suggests that the increase in the incidence of depression conferred by MS is greater for men than for women. This finding requires replication in other population-based cohorts, but its implications for clinical management of MS are considerable. Examination of the underlying reasons, such as lower perceived levels of social support, ${ }^{39}$ lower self-efficacy, or fewer health-seeking behaviors among men with MS, is warranted. Longitudinal studies of depressive symptoms over the course of disease could identify periods of increased risk and potential risk factors.

Strengths of this study include its large size, population-based nature, and use of concurrent matched controls. However, limitations should be recognized. We used administrative data that are not collected for research, and lack clinical details such as clinical course and disability status, although we have validated our approaches to identifying MS cases and psychiatric comorbidities previously.,16 Our approach only captures individuals who have sought care and have had their psychiatric conditions recognized through the health system, ${ }^{16}$ but this potential underascertainment applies to both the MS and comparator populations. The age at MS diagnosis was later than often reported, possibly because some prevalent cases were identified when our data began in the 1990s or when they emigrated into the province rather than when they were actually diagnosed. We reported $P^{2}$ as a measure of heterogeneity, but $I^{2}$ tends toward $100 \%$ when the sample size is large and precision is high, ${ }^{40}$ thus heterogeneity was likely overestimated.

We confirmed that psychiatric comorbidity is common in MS; the incidence and prevalence of all conditions studied was higher than in a matched population. This suggests a nonspecific effect of MS on psychiatric comorbidity; MS increases the risk of all psychiatric disorders. From a policy perspective, this implies the need for general psychiatric support rather than illness-specific strategies. While the incidence and prevalence of these conditions changed little over 10 years, their increased frequency in the MS population as compared to the matched population indicates the increased burden these conditions impose on the 
MS population. While women with MS face a particularly high risk of depression and anxiety, men with MS face a disproportionately greater increase in the risk of depression when they develop MS.

\section{AUTHOR CONTRIBUTIONS}

R.A.M. takes responsibility for the integrity of the data and the accuracy of the data analysis. The analysts and principal investigators at each site had full access to the data at each site (BC: Helen Tremlett, Aruni Tennakoon, Stella Leung; MB: Ruth Ann Marrie, Aruni Tennakoon; QC: Christina Wolfson, Bin Zhu; NS: John Fisk, Yan Wang). Ruth Ann Marrie, John Fisk, Christina Wolfson, Helen Tremlett, and Sharon Warren designed the study and obtained funding. All authors contributed to the interpretation of the data. Ruth Ann Marrie drafted the manuscript. All authors revised the manuscript and approved of the final version to be published.

\section{ACKNOWLEDGMENT}

All inferences, opinions, and conclusions drawn in this publication are those of the authors and do not reflect the opinions or policies of the Data Stewards. No official endorsement by Manitoba Health, Population Data BC, Pharmanet, the Regie D'Assurance Maladie du Quebec, or The Commission d'accès à l'information (CAI) of Quebec is intended or should be inferred. Some data used in this report were made available by Health Data Nova Scotia of Dalhousie University. Although this research is based on data obtained from the Nova Scotia Department of Health and Wellness, the observations and opinions expressed are those of the authors and do not represent those of either Health Data Nova Scotia or the Departmen of Health and Wellness. Contributors: Patricia Caetano, PhD (University of Manitoba, policy consultant); Nicholas Hall, BSc (University of Manitoba, study coordinator); Feng Zhu, PhD (University of British Columbia, analytic support); Elaine Kingwell, $\mathrm{PhD}$ (University of British Columbia, study coordination support); Karen Stadnyk, MSc (Dalhousie University, study coordinator); and Yan Wang (Dalhousie University, analytic support).

\section{STUDY FUNDING}

This study was supported (in part) by the Canadian Institutes of Health Research (CIBG 101829), the Rx\&D Health Research Foundation, a Don Paty Career Development award from the Multiple Sclerosis Society of Canada (to R.A.M.), and Manitoba Research Chair from Research Manitoba (to R.A.M.). The funding source(s) had no role in the study design, collection, analysis or interpretation of the data, or in the decision to submit the article for publication.

\section{DISCLOSURE}

R. Marrie receives research funding from Canadian Institutes of Health Research, Research Manitoba, Multiple Sclerosis Society of Canada, Multiple Sclerosis Scientific Foundation, National Multiple Sclerosis Society, Rx\&D Health Research Foundation, and has conducted clinical trials funded by Sanofi-Aventis. J. Fisk receives funding from the Canadian Institutes of Health Research (CIHR), MS Society of Canada, and National Multiple Sclerosis Society, and has received speaker honoraria from EMD Serono $(2013,2014)$. H. Tremlett is funded by the Multiple Sclerosis Society of Canada (Don Paty Career Development Award); is a Michael Smith Foundation for Health Research Scholar and the Canada Research Chair for Neuroepidemiology and Multiple Sclerosis. She has received research support from the National Multiple Sclerosis Society, the Canadian Institutes of Health Research, and the UK MS Trust and speaker honoraria and/or travel expenses to attend conferences from the Consortium of MS Centres (2013), the National MS Society (2012, 2014), Bayer Pharmaceuticals (2010), Teva Pharmaceuticals (2011), ECTRIMS (2011, 2012, 2013, 2014), UK MS Trust (2011), the Chesapeake Health Education Program, US Veterans Affairs (2012), Novartis Canada (2012), Biogen Idec (2014), and American Academy of Neurology $(2013,2014,2015)$. Unless otherwise stated, all speaker honoraria are either donated to an MS charity or to an unrestricted grant for use by her research group. C. Wolfson receives research funding from the Multiple Sclerosis Society of Canada, Canadian Institutes of Health
Research, Canada Foundation for Innovation, and the National Multiple Sclerosis Society. She has received a speaking honorarium from Novartis Pharmaceuticals. S. Warren receives research funding from the CIHR. A. Tennakoon and S. Leung report no disclosures relevant to the manuscript. S. Patten has received honoraria for reviewing investigatorinitiated grant applications submitted to Lundbeck and Pfizer and has received speaking honoraria from Teva and Lundbeck. He is the recipient of a salary support award (Senior Health Scholar) from Alberta Innovates, Health Solutions and receives research funding from the Canadian Institutes for Health Research, Alberta Health Services and the Alberta Collaborative Research Grants Initiative. Go to Neurology.org for full disclosures.

Received April 21, 2015. Accepted in final form August 6, 2015.

\section{REFERENCES}

1. Marrie RA, Horwitz R, Cutter G, Tyry T. Cumulative impact of comorbidity on quality of life in MS. Acta Neurol Scand 2012;125:180-186.

2. Mohr DC, Goodkin DE, Likosky W, Gatto N, Baumann KA, Rudick RA. Treatment of depression improves adherence to interferon beta- $1 \mathrm{~b}$ therapy for multiple sclerosis. Arch Neurol 1997;54:531-533.

3. Marrie R, Reider N, Cohen J, et al. The incidence and prevalence of psychiatric disorders in multiple sclerosis: a systematic review. Mult Scler J 2015;21:305-317.

4. Marrie RA, Fisk JD, Yu BN, et al. Mental comorbidity and multiple sclerosis: validating administrative data to support population-based surveillance. BMC Neurol 2013;13:16.

5. Horton M, Rudick RA, Hara-Cleaver C, Marrie RA. Validation of a self-report comorbidity questionnaire for multiple sclerosis. Neuroepidemiology 2010;35:83-90.

6. Marrie RA, Horwitz RI, Cutter G, Tyry T, Campagnolo D, Vollmer T. The burden of mental comorbidity in multiple sclerosis: frequent, underdiagnosed, and under-treated. Mult Scler 2009; 15:385-392.

7. Joffe RT, Lippert GP, Gray TA, Sawa G, Horvath Z. Mood disorder and multiple sclerosis. Arch Neurol 1987;44:376-378.

8. Johannson V, Lundholm C, Hillert J, et al. Multiple sclerosis and psychiatric disorders: comorbidity and sibling risk in a nationwide Swedish cohort. Mult Scler J 2014; 20:1881-1891.

9. Thielscher C, Thielscher S, Kostev K. The risk of developing depression when suffering from neurological diseases. Ger Med Sci 2013;11:Doc02.

10. Dormuth CR, Hemmelgarn BR, Paterson JM, et al. Use of high potency statins and rates of admission for acute kidney injury: multicenter, retrospective observational analysis of administrative databases. Br Med J 2013;346: f880.

11. British Columbia Ministry of Health [creator] [2012]. Discharge Abstract Database (Hospital Separations) [online]. Available at: http://www.popdata.bc.ca/data. Accessed April 1, 2015.

12. British Columbia Ministry of Health [creator] [2012]. Medical Services Plan (MSP) [online]. Available at: http://www.popdata.bc.ca/data. Accessed April 1, 2015.

13. British Columbia Ministry of Health [creator] [2012]. Consolidation File (MSP Registration \& Premium Billing) [online]. Available at: http://www.popdata.bc.ca/data. Accessed April 1, 2015.

14. Marrie RA, Yu N, Blanchard JF, Leung S, Elliott L. The rising prevalence and changing age distribution of multiple sclerosis in Manitoba. Neurology 2010;74:465-471. 
15. Marrie RA, Fisk J, Stadnyk K, et al. The incidence and prevalence of multiple sclerosis in Nova Scotia, Canada. Can J Neurol Sci 2013;40:824-831.

16. Marrie RA, Fisk JD, Stadnyk KJ, et al. Performance of administrative case definitions for comorbidity in multiple sclerosis in Manitoba and Nova Scotia. Chronic Dis Inj Can 2014;34:145-153.

17. Yasui Y, Liu Y, Neglia J, et al. A methodological issue in the analysis of second-primary cancer incidence in longterm survivors of childhood cancers. Am J Epidemiol 2003;158:1108-1113.

18. Neyeloff J, Fuchs S, Moreira L. Meta-analyses and Forest plots using a Microsoft Excel spreadsheet: step-by-step guide focusing on descriptive data analysis. BMC Res Notes 2012;5:52.

19. Patten SB, Berzins S, Metz LM. Challenges in screening for depression in multiple sclerosis. Mult Scler J 2010;16: 1406-1411.

20. Demakis GJ, Buchanan R, Dewald L. A longitudinal study of cognition in nursing home residents with multiple sclerosis. Disabil Rehabil 2009;31:1734-1741.

21. Marrie RA, Yu BN, Leung S, et al. The utility of administrative data for surveillance of comorbidity in multiple sclerosis: a validation study. Neuroepidemiology 2013;40:85-92.

22. Nuyen J, Schellevisa FG, Satarianob WA, et al. Comorbidity was associated with neurologic and psychiatric diseases: a general practice-based controlled study. J Clin Epidemiol 2006;59:1274-1284.

23. Kessler RC, Berglund P, Demler O, Jin R, Merikangas KR, Walters EE. Lifetime prevalence and age-of-onset distributions of DSM-IV disorders in the National Comorbidity Survey Replication. Arch Gen Psychiatry 2005;62:593-602.

24. Kingwell E, van der Kop M, Zhao Y, et al. Relative mortality and survival in multiple sclerosis: findings from British Columbia, Canada. J Neurol Neurosurg Psychiatry 2012;83:61-66.

25. Ferrari AJ, Charlson FJ, Norman RE, et al. Burden of depressive disorders by country, sex, age, and year: findings from the Global Burden of Disease Study 2010. PLoS Med 2013;10:e1001547.

26. Baxter AJ, Vos T, Scott KM, et al. The regional distribution of anxiety disorders: implications for the Global Burden of Disease Study, 2010. Int J Methods Psychiatr Res 2014;23:422-438.

27. Vasiliadis HM, Lesage A, Adair C, Boyer R. Service use for mental health reasons: cross-provincial differences in rates, determinants, and equity of access. Can J Psychiatry 2005; 50:614-619.

28. Kisely S, Lin E, Gilbert C, Smith M, Campbell LA, Vasiliadis HM. Use of administrative data for the surveillance of mood and anxiety disorders. Aust NZ J Psychiatry 2009; 43:1118-1125.

29. Patten SB, Wang JL, Williams JV, et al. Descriptive epidemiology of major depression in Canada. Can J Psychiatry 2006;51:84-90.

30. Schaffer A, Cairney J, Cheung A, Veldhuizen S, Levitt A. Community survey of bipolar disorder in Canada: lifetime prevalence and illness characteristics. Can J Psychiatry 2006;51:9-16.

31. Supina AL, Patten SB. Self-reported diagnoses of schizophrenia and psychotic disorders may be valuable for monitoring and surveillance. Can J Psychiatry 2006;51: 256-259.

32. Steel Z, Marnane C, Iranpour C, et al. The global prevalence of common mental disorders: a systematic review and meta-analysis 1980-2013. Int J Epidemiol 2014;43: 476-493.

33. Tandon R, Keshavan MS, Nasrallah HA. Schizophrenia, "just the facts": what we know in 2008. 2. Epidemiology and etiology. Schizophr Res 2008;102:1-18.

34. Carta MG, Moro MF, Lorefice L, et al. The risk of bipolar disorders in multiple sclerosis. J Affect Disord 2014;155: 255-260.

35. Arnold LM. Gender differences in bipolar disorder. Psychiatr Clin North Am 2003;26:595-620.

36. Beiske AG, Svensson E, Sandanger I, et al. Depression and anxiety amongst multiple sclerosis patients. Eur J Neurol 2008; 15:239-245.

37. Dahl OP, Stordal E, Lydersen S, Midgard R. Anxiety and depression in multiple sclerosis: a comparative populationbased study in Nord-Trøndelag County, Norway. Mult Scler J 2009;15:1495-1501.

38. Patten SB, Beck CA, Williams JVA, Barbui C, Metz LM. Major depression in multiple sclerosis. Neurology 2003; 61:1524-1527.

39. Jensen MP, Smith AE, Bombardier CH, Yorkston KM, Miro J, Molton IR. Social support, depression, and physical disability: age and diagnostic group effects. Disabil Health J 2014;7:164-172.

40. Rucker G, Schwarzer G, Carpenter JR, Schumacher M. Undue reliance on $\mathrm{I}(2)$ in assessing heterogeneity may mislead. BMC Med Res Methodol 2008;8:79.

\section{Subspecialty Alerts by E-mail!}

Customize your online journal experience by signing up for e-mail alerts related to your subspecialty or area of interest. Access this free service by visiting Neurology.org/site/subscriptions/etoc.xhtml or click on the "E-mail Alerts" link on the home page. An extensive list of subspecialties, methods, and study design choices will be available for you to choose from-allowing you priority alerts to cutting-edge research in your field! 


\section{Neurology}

Differences in the burden of psychiatric comorbidity in MS vs the general population Ruth Ann Marrie, John D. Fisk, Helen Tremlett, et al.

Neurology 2015;85;1972-1979 Published Online before print October 30, 2015 DOI 10.1212/WNL.0000000000002174

This information is current as of October 30, 2015

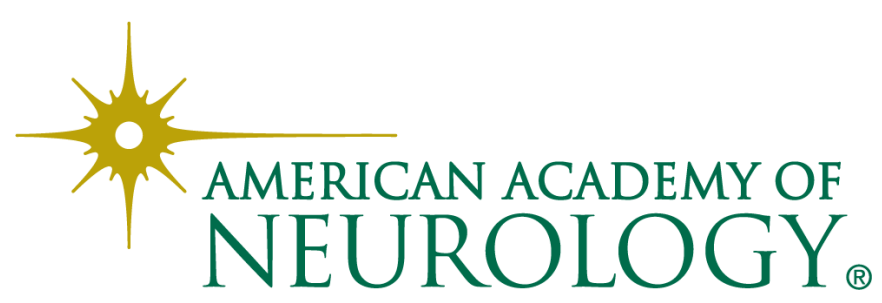




\section{Updated Information \& Services}

\section{Supplementary Material}

\section{References}

\section{Citations}

Subspecialty Collections

\section{Permissions \& Licensing}

\section{Reprints}

including high resolution figures, can be found at: http://n.neurology.org/content/85/22/1972.full

Supplementary material can be found at: http://n.neurology.org/content/suppl/2015/10/30/WNL.0000000000002 174.DC1

http://n.neurology.org/content/suppl/2015/10/30/WNL.0000000000002 174.DC2

http://n.neurology.org/content/suppl/2016/02/29/WNL.0000000000002 174.DC3

This article cites 36 articles, 3 of which you can access for free at: http://n.neurology.org/content/85/22/1972.full\#ref-list-1

This article has been cited by 3 HighWire-hosted articles: http://n.neurology.org/content/85/22/1972.full\#\#otherarticles

This article, along with others on similar topics, appears in the following collection(s):

All Psychiatric disorders

http://n.neurology.org/cgi/collection/all_psychiatric_disorders

Burden of disease

http://n.neurology.org/cgi/collection/burden_of_disease

Cohort studies

http://n.neurology.org/cgi/collection/cohort_studies

Incidence studies

http://n.neurology.org/cgi/collection/incidence_studies

Multiple sclerosis

http://n.neurology.org/cgi/collection/multiple_sclerosis

Prevalence studies

http://n.neurology.org/cgi/collection/prevalence_studies

Information about reproducing this article in parts (figures,tables) or in its entirety can be found online at:

http://www.neurology.org/about/about_the_journal\#permissions

Information about ordering reprints can be found online:

http://n.neurology.org/subscribers/advertise

Neurology ${ }^{\circledR}$ is the official journal of the American Academy of Neurology. Published continuously since 1951, it is now a weekly with 48 issues per year. Copyright @ 2015 American Academy of Neurology. All rights reserved. Print ISSN: 0028-3878. Online ISSN: 1526-632X.

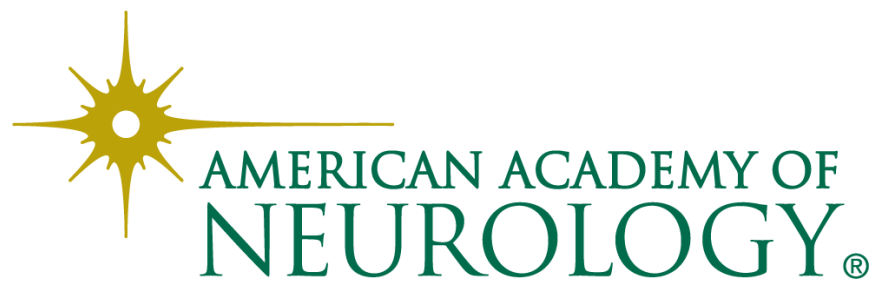

